\title{
Assessment of health-related quality of life of Bangladeshi patients with type 2 diabetes using the EQ-5D: a cross-sectional study
}

Farzana Saleh ${ }^{1 *}$, Ferdous Ara $^{2}$, Shirin Jahan Mumu ${ }^{3}$ and Md Abdul Hafez ${ }^{4}$

\begin{abstract}
Background: The management of diabetes requires a fundamental change in the lifestyle of patients, and one of the important outcome criteria is the quality of life. We assessed the health-related quality of life (HR-QoL) and examined the factors associated with it in type 2 diabetes.
\end{abstract}

Methods: An analytical cross-sectional study was conducted among 500 type 2 diabetes patients (age $>25$ years and duration of diabetes $>1$ year). They were selected conveniently from the Out-Patient department of the Bangladesh Institute of Health Sciences Hospital. The HR-QoL was assessed using an adapted and validated Bangla version of the EQ-5D (๑ 1990 EuroQol Group. EQ-5D ${ }^{\mathrm{TM}}$ ) questionnaire. It has five domains: mobility, self-care, usual activities, pain/ discomfort, and anxiety/depression and two levels (problem and no problem) on each dimension. The responses to the EQ-5D were further translated into a single summary EQ-5D index using the UKTTO value set.

Results: Of the patients, $50.2 \%$ were female, and $49.4 \%$ were aged $>55$ years. Only $28.4 \%$ had completed higher secondary education, and $50.8 \%$ were from lower-middle-income families. Around $78.8 \%$ either had overweight or were obese. About $50.4 \%$ had problems in mobility, $28.2 \%$ in self-care, $47.6 \%$ in usual activities, $72.8 \%$ in pain/ discomfort, and $73.6 \%$ in anxiety/depression. Results of binary logistic regression analysis showed that age, gender, lower-middle income, and $\mathrm{HbA}_{c}$ c were significantly $(\mathrm{p}<0.05)$ associated with mobility. Self-care was significantly $(p<0.05)$ related to age, family history and duration of diabetes mellitus (DM). Gender, family history of DM, and lower-middle income had a significant $(p<0.05)$ association with usual activities. Pain was significantly $(p<0.05)$ associated with age, lower-middle income, and upper-middle income. Rural area, higher education, and $\mathrm{HbA1}_{C}$ were significantly $(p<0.05)$ related to anxiety. Results of multiple linear regression analysis showed that age $(p=0.0001)$, female gender $(p=0.0001)$, and prescribed treatment $(p=0.048)$ were associated with the EQ-5D index.

Conclusions: The large majority (73\%) of the patients had problems in pain/discomfort and anxiety/depression; $50 \%$ had problems in mobility and usual activities; and three in ten in self-care. Age, female gender, income, education, family history and duration of DM, and prescribed treatment are important factors that are associated with the HR-QoL in type 2 diabetes.

Keywords: Cross-sectional study, EQ-5D, Health-related quality of life, Quality of life, Type 2 diabetes, Bangladesh

\footnotetext{
*Correspondence: farzanasaleh_sumona@yahoo.com

1 Department of Community Nutrition, Bangladesh University of Health

Sciences (BUHS), 125/1 Darussalam Mirpur 1, Dhaka 1216, Bangladesh

Full list of author information is available at the end of the article
} 


\section{Background}

Diabetes is a chronic disease with a considerable impact on the health status and quality of life and is considered an urgent public-health issue because of its epidemic perspective. According to the World Health Organization (WHO), compared to the developed world, developing countries have a larger burden of diabetes [1]. Due to its low awareness among the public in developing countries, it is certain that they will face the impact of diabetes waves in coming years. Now a day, the number of type 2 diabetes people is increasing in every country, and in every $6 \mathrm{~s}$, a person dies from diabetes [2].

Globally, the majority of the 382 million people with diabetes are aged $40-59$ years; $80 \%$ of them live in lowand middle-income countries; and the percentage of people with type 2 diabetes will increase to $55 \%$ in 2035 [2].

Like all other developed and developing countries, the prevalence and the incidence of type 2 diabetes mellitus (DM) are also increasing in Bangladesh. In 2013, its prevalence in Bangladesh was estimated to be $7.11 \%$ by the International Diabetes Federation (IDF) [2]. By 2030, the number of diabetes patients is expected to rise to 11.1 million; this explosion will place the country among the top seven countries of the world in 2030 [3].

The WHO in 1948 defined health from a new perspective, not only by the absence of disease and infirmity, but also by the presence of physical, mental and social well-being [4]. The quality of life is an important health outcome in its own right, representing the ultimate goal of all health interventions. Clinicians and public-health officials have used the health-related quality of life (HRQoL) and well-being to measure the effects of chronic illness, treatments, and short- and long-term disabilities [5]. Persons with diabetes have lower quality of life than persons without chronic illnesses; however, the quality of their life is better compared to patients with other serious chronic diseases [6].

A complete cure of chronic diabetes cannot be achieved, and as such, it has a considerable impact on key aspects of patients' well-being. Although clinical measures provide a good estimate of disease control, the ultimate objective of diabetes care is to improve the patient's HR-QoL.

The EuroQol 5D (EQ-5D), a generic measure of HRQoL, is widely used for determining the quality of life. Some studies have as well used it for estimating the HRQoL of patients with type 2 diabetes in Western and Asian countries. The FIELD study reported that that the EQ-5D index is an independent predictor of mortality risk, future vascular events, and other complications in patients with type 2 diabetes [7]. The EQ-5D was used in Japan [8] and Korea [9] for measuring the HR-QoL in patients with type 2 diabetes.
Several studies have identified several factors that influence the HR-QoL in patients with diabetes [8-13]. The measurement of HR-QoL indicates a comprehensive evaluation of the patient's health status which would provide additional information to laboratory data and subjective symptoms.

Awareness of diabetes among patients in developing countries like Bangladesh is still poor [14]. Despite its high prevalence and the importance of HR-QoL in the management of diabetes, little is known about the HRQoL of patients with diabetes in Bangladesh. Against this background, the present study was conducted to assess the HR-QoL of Bangladeshi patients with type 2 diabetes.

\section{Methods}

This analytical cross-sectional study was conducted among 500 patients with type 2 diabetes. They were selected conveniently from the Out-Patient department (OPD) of the Bangladesh Institute of Health Sciences (BIHS) hospital. The minimum required sample-size was calculated using the formula $n=z^{2} p q / d^{2}$; where, $\mathrm{z}=1.96, \mathrm{p}=$ the expected rates of problem in health-related quality of life, i.e. $31 \%$ [9]; $q=(100-p)$, and $\mathrm{d}=$ allowable error of known prevalence, i.e. $4 \%$. Patients who were aged $>25$ years, having diabetes for at least 1 year (from the date of interview) were included in the study. Patients who had other medical complications or who were unable to answer a short list of simple questions (sociodemographic information, such as name, address, disease complications, etc.) were excluded from the study.

\section{Instruments}

An interviewer-administered questionnaire was designed to know and assess the level of the patient's HR-QoL. Information on age, sex, educational qualification, occupation, monthly income, duration of diabetes, family history of diabetes, acquisition of information relating to diabetes, and prescribed treatment for patients was collected by interviewing the patients. A checklist was used for collecting HbA1c data from the patients' guidebook. The checklist means an instrument used when observing some situation. The researcher/interviewers put tick marks against the particular point or wrote down what he/she observed.

\section{Anthropometric measurements}

Anthropometric measurements included weight and height of the patients. Body-weight in light clothes was measured to the nearest $0.1 \mathrm{~kg}$ using a Sohenle mechanical weighing scale (Soehnle-Waagen $\mathrm{GmbH} \&$ Co. KG, Wilhelm-Soehnle-Strabe 2, D-71540 Murrhardt/Germany). Height was measured to the nearest $0.5 \mathrm{~cm}$ using 
a portable, locally-manufactured stadiometer, with patients standing upright on a flat surface without shoes, and the back of the heels and the occiput remaining on the stadiometer. The questionnaire was pretested before its finalization.

\section{Measurement of HR-QoL}

The HR-QoL was assessed using an adapted and validated Bangla (local language) version of the EQ-5D [15]. This generic instrument has five dimensions, such as mobility, self-care, usual activities, pain/discomfort, and anxiety/depression. Each dimension has three levels, such as no problem, some problems, and extreme problems. For binary logistic analysis, the level of each domain was divided into two levels, such as no problem and problems (by collapsing the other levels). However, according to the suggestion of the EuroQol group, sometimes it is more convenient to dichotomize the EQ-5D levels into 'no problem' (i.e. level 1) and 'problems' (i.e. level 2 and 3) [15]. In our study, we faced a very few number of reported level 3 problems.

The developers of the EQ-5D have generated value sets in several countries to calculate a preference-based index for the 243 health states defined by responses to the five questions of the EQ-5D, using a scale on which 0.0 represents being dead and 1.0 full health. Values of the index can be negative for states that are deemed to be 'worse than death': so for example, the minimum value in the UK-based value set is -0.59 , which represents the worst possible health state (i.e. 33,333) [16]. As there is no value set based on time trade off developed for the South-East Asian population we have used the time trade off (TTO) method conducted in the United Kingdom [16] i.e., UK TTO most commonly used sets currently available for the EQ-5D [16].

\section{Socioeconomic classifications}

The patients were grouped according to the 2006 percapita gross national income (GNI) and the World Bank calculations [17] as follows: low income: US\$ $\leq 905$ or Tk $\leq 4906$; lower-middle income: US\$ 906-3595 or Tk 4907-19,488; upper-middle income: US\$ 3596-11115 or Tk 19489-60252; and high income: US $\$ 11,116$ or Tk $\geq 60,252$.

\section{Analysis of data}

Frequencies and mean \pm SD were calculated for descriptive analysis. Binary logistic regression was used for examining the factors associated with the EQ-5D domains. The 12 independent variables used for each proposed model were: age, gender, habitat, education, occupation, income, family history of diabetes, duration of diabetes, acquisition of information, BMI, HbA1c, and prescribed treatment. Of these, seven independent variables were significantly associated with the EQ-5D domains, and only significant results are presented in the tables. Multiple linear regression was used for finding out the factors associated with the EQ-5D index. Statistical tests were considered significant at $p$ value of $\leq 5 \%$ $(\leq 0.05)$.

In the study, acquisition of information defined as patients was obtained information on diabetes from physicians, nurses, health educators, and nutritionists and also from different types of tools, such as magazine, leaflet, guidebook, and TV shows. Prescribed treatment implied prescriptions made by the respective physicians.

\section{Ethical aspects}

Informed written consent was obtained from all the respondents after fully explaining the nature, purpose, and procedures used for the study to them. Ethical approval was obtained from the ethics and research review committees of the Diabetic Association of Bangladesh.

\section{Results}

Table 1 presents the sociodemographic and other relevant characteristics of the patients. Their mean age was $54.2( \pm 11.2)$ years. Of the patients, $50.2 \%$ were female; $49.4 \%$ were aged $>55$ years; $28.4 \%$ had completed higher secondary education; $79.8 \%$ were from the urban area; $29.8 \%$ were employed; $46.6 \%$ were homemakers; and 40.4 and $50.8 \%$ were from upper-middle- and lowermiddle-income families respectively. The large majority $(70.4 \%)$ of the patients had a positive family history of diabetes, and $47.8 \%$ had diabetes for 5 years or less. Twenty-three percent did not get any information on diabetes from any source. The mean $\mathrm{HbA}_{1} \mathrm{c}(\%)$ of the patients was $6.45( \pm 1.81)$. According to Asian BMI [18] cut-off, $52.8 \%$ were at an increased risk and $26 \%$ at a high risk. More than half (57\%) were prescribed for oral hypoglycemic agent (OHA) and $31 \%$ for both insulin and OHA.

The profile of the HR-QoL of the patients by domain is presented in Fig. 1. Figure 1 shows that about $44 \%$ of the patients had some problems in mobility, $27 \%$ in selfcare, $44 \%$ in usual activities, $57.8 \%$ in pain/discomfort, and $59.4 \%$ in anxiety/depression. Extreme problem in mobility was observed among $6.4 \%$ of the patients, $1.2 \%$ in self-care, $3.6 \%$ in usual activities, $15 \%$ in pain/discomfort, and $14.2 \%$ in anxiety/depression.

Results of binary logistic regression analysis showed that the upper-middle-income group had two times likely to have problems in mobility compared to the other groups $(\beta=1.007 ; \mathrm{p}=0.022$; odds ratio $\mathrm{OR}=2.738 ; 95 \%$ CI 1.160-6.463). Age showed a significant association 
Table 1 Characteristics of patients $(n=500)$

\begin{tabular}{|c|c|}
\hline \multicolumn{2}{|l|}{ Parameter } \\
\hline Age (years) & $54.21 \pm 11.22$ \\
\hline $25-39$ & $39(7.8)$ \\
\hline $40-54$ & $214(42.8)$ \\
\hline$\geq 55$ & $247(49.4)$ \\
\hline \multicolumn{2}{|l|}{ Gender } \\
\hline Female & $251(50.2)$ \\
\hline Male & $249(49.8)$ \\
\hline \multicolumn{2}{|l|}{ Education } \\
\hline Illiterate & $105(21)$ \\
\hline Primary to 8th grade & $154(30.8)$ \\
\hline SSC to HSC & $142(28.4)$ \\
\hline Graduate and above & $99(19.8)$ \\
\hline \multicolumn{2}{|l|}{ Habitat } \\
\hline Urban & $399(79.8)$ \\
\hline Rural & $95(19)$ \\
\hline Semi-urban & $6(1.2)$ \\
\hline \multicolumn{2}{|l|}{ Occupation } \\
\hline Service & $78(15.6)$ \\
\hline Business & $71(14.2)$ \\
\hline Homemaker & $233(46.6)$ \\
\hline Others (labor/unemployed) & $118(23.6)$ \\
\hline \multicolumn{2}{|l|}{ Monthly income (US\$) } \\
\hline High income $(\geq 11,115)$ & $35(7)$ \\
\hline Upper-middle income $(3596-11,115)$ & $202(40.4)$ \\
\hline Lower-middle income (906-3595) & $254(50.8)$ \\
\hline Low income $(\leq 905)$ & $9(1.8)$ \\
\hline \multicolumn{2}{|l|}{ Family history of DM } \\
\hline No & $132(26.4)$ \\
\hline Yes & $352(70.4)$ \\
\hline Do not know & $16(3.2)$ \\
\hline \multicolumn{2}{|l|}{ Duration (years) of DM } \\
\hline$\leq 5$ & $239(47.8)$ \\
\hline $6-12$ & $173(34.6)$ \\
\hline $13-18$ & $50(10)$ \\
\hline$>18$ & $37(7.4)$ \\
\hline \multicolumn{2}{|l|}{ Acquisition of information } \\
\hline Yes & $384(77)$ \\
\hline No & $115(23)$ \\
\hline \multicolumn{2}{|l|}{ Prescribed treatment } \\
\hline $\mathrm{OHA}$ & $287(57.4)$ \\
\hline Insulin & $44(8.8)$ \\
\hline $\mathrm{OHA}+$ insulin & $155(31)$ \\
\hline Diet & $14(2.8)$ \\
\hline $\mathrm{HbA}_{1 \mathrm{c}}(\%)$ & $6.45 \pm 1.81$ \\
\hline Body mass index $\left(\mathrm{kg} / \mathrm{m}^{2}\right)$ & $26.1 \pm 6.7$ \\
\hline Underweight & $5(1)$ \\
\hline Acceptable risk & 99 (19.8) \\
\hline Increased risk & $264(52.8)$ \\
\hline High risk & $130(26)$ \\
\hline
\end{tabular}

Results are expressed as number (\%) and mean \pm SD; US\$ $1=$ Tk 77.47 $\mathrm{OHA}$ oral hypoglycemic agent $(\beta=0.039 ; \mathrm{p}=0.002 ; \mathrm{OR}=1.039 ; 95 \%$ CI 1.014-1.065) with self-care. Having a positive family history of diabetes $(\beta=-0.867 ; \mathrm{p}=0.001$; OR $=0.420 ; 95 \% \mathrm{CI} 0.250$ $0.706)$ and the duration of diabetes $(\beta=0.042 ; \mathrm{p}=0.021$; $\mathrm{OR}=1.043 ; 95 \%$ CI 1.006-1.082) showed a significant association with self-care. The female group had three times more likely to have problems in usual activities compared to the male $(\beta=1.322 ; \mathrm{p}=0.022$; OR $=3.751$; 95 \% CI 1.207-11.658). The upper-middle-income group was two times likely to have problems with usual activities compared to the other groups $(\beta=0.974 ; \mathrm{p}=0.024$; $\mathrm{OR}=2.648$; $95 \%$ CI 1.136-6.173). The positive family history of diabetes also showed a significant association with usual activities $(\beta=-0.767 ; \mathrm{p}=0.002$; OR $=0.464$; $95 \%$ CI 0.288-0.747). Age showed a significant association $(\beta=0.050 ; \mathrm{p}=0.0001$; OR $=1.051 ; 95 \%$ CI $1.025-$ 1.079) with pain/discomfort. The upper-middle-income group $(\beta=1.034 ; \mathrm{p}=0.015$; OR $=2.811$; $95 \% \mathrm{CI} 1.227-$ $6.441)$ and the lower-middle-income group ( $\beta=0.946$; $\mathrm{p}=0.023 ; \mathrm{OR}=2.576 ; 95 \%$ CI $1.138-5.832)$ were two times likely to have problems with pain/discomfort compared to the other groups. The rural patients felt anxiety/depression significantly compared to the urban patients $(\beta=-0.588 ; \mathrm{p}=0.042$; OR $=0.555 ; 95 \% \mathrm{CI}$ $0.315-0.978)$. The higher education group showed a significant association with anxiety/depression $(\beta=-0.960$; $\mathrm{p}=0.028$; OR $=0.383$; 95 \% CI 0.162-0.902) (Table 2).

Twelve independent variables together (irrespective of significant or non-significant) showed about 31.4, 26.8, $22.4,21.3$, and $16 \%$ (Nagelkerke's $\mathrm{R}^{2}$ ) of variation in mobility, self-care, usual activities, pain/discomfort, and anxiety/depression respectively (Table 3 ).

Results of multiple linear regression analyses for the EQ-5D index are presented in Table 4, and the results showed that the overall multiple regression model achieved an adjusted $\mathrm{R}^{2}$ of $0.20 ; \mathrm{p}=0.0001$. In this model, gender had an influence on the HR-QoL $(\mathrm{p}=0.0001)$. Other sociodemographic factors, i.e. older age, were associated with the lower quality of life $(\mathrm{p}=0.0001)$ and higher education with the better quality of life $(\mathrm{p}=0.025)$. Prescribed treatment was also significantly $(\mathrm{p}=0.048)$ associated with the quality of life.

\section{Discussion}

The quality of life is gradually gaining importance as the clinical or physiological outcome parameter. This study provides a perspective of HR-QoL among Bangladeshi patients with type 2 diabetes.

In the present study, more than half of the individuals with type 2 diabetes reported 'some problems' in the pain/discomfort (57.8\%) and anxiety/depression (59.4\%) dimensions whereas it was $44 \%$ in the dimensions of mobility and usual activities and $27 \%$ in self-care. The 


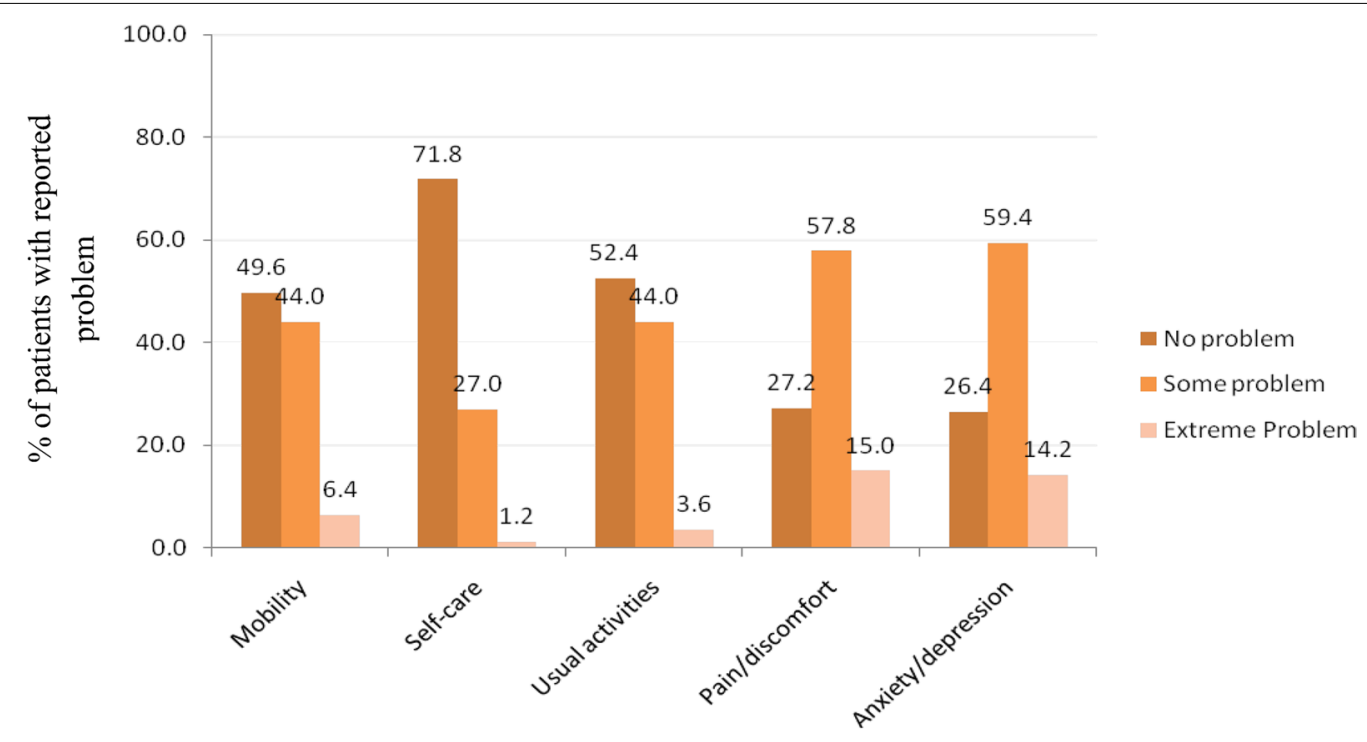

Five domains of the health related QoL (HR-QoL)

Fig. 1 Profile of health-related quality of life among patients $(n=500)$

percentage in the dimensions of mobility, usual activities, and self-care was comparatively low compared to other two dimensions. This finding was inconsistent with the reports from Japan [8], Korea [9], and Singapore [10]. The percentages of Japanese patients reported problems were $21.2 \%$ for mobility, $2.8 \%$ for self-care, $17.3 \%$ for usual activities, $35.7 \%$ for pain/discomfort, and $19.7 \%$ for anxiety/depression [8]. In Korea, some changes were observed in the HR-QoL among patients with diabetes [9]. Thirty percent of patients in Singapore had problems in pain/discomfort and anxiety/depression [10]. In Oman, patients with type 2 diabetes had the moderate HR-QoL [11]. The differences in the results with other populations may be due to the HR-QoL which is a timedependent variable and should be repeatedly measured in patients with type 2 diabetes to ensure reliable estimations. Discontinuation of follow-up by patients, the quality of diabetes care, and the availability of access to support services could be the reasons of observing the change in the HR-QoL.

We also predicted that the HR-QoL decreases because of some other factors. Evidence shows that the impaired HR-QoL is associated with age $[8,9,11-13]$ and gender $[9,12,13]$. In the present study, the female patients had a 3-5-time higher risk of less mobility and usual activities compared to the male patients.

In our study, income also played a significant role in the HR-QoL. The upper-middle- and lower-middle-income groups in particular had less mobility and usual activities, although they had problems in pain. However, income was not found as an important factor in other studies [8-13].

In our study, the duration of diabetes was significantly associated with the self-care domain only, and the results revealed that the increase in the duration of DM decreased self-care. Consistent with findings of a study, patients with type 2 diabetes of more than 5 years had less satisfaction in self-care [11].

Patients with a family history of DM were satisfied with the HR-QoL domains self-care and usual activity. A possible explanation could be that a previous family history of diabetes is likely to increase awareness of the disease among other members of the family. Patients get information from them about its management. However, social support and family history of DM empower the patient's individual attitudes, with the end result of enhancing the quality of life and reducing the severity of illness.

In the present study, higher educated and rural patients had a good HR-QoL. Similarly, Omani patients with 6 years of education had a significantly better quality of life compared to other patients with lower level of education [11]. Education gives power to the patient for self-management and has become a cornerstone of quality-oriented diabetes care. In our society, we notice that rural people are hard-workers, and their lifestyle and dietary habits are still better (especially with respect to consuming more fresh vegetables and other foods; doing hard physical activities) compared to urban people. Simultaneously, our government has been providing 
Table 2 Binary logistic regression for estimating odds ratio and $95 \%$ confidence interval for assessing HR-QoL (with 'no problem' in five domains as the reference category) by selected factors

\begin{tabular}{|c|c|c|c|c|c|}
\hline \multirow[t]{2}{*}{$\begin{array}{l}\text { Independent } \\
\text { variable }\end{array}$} & \multirow[t]{2}{*}{$\beta$} & \multirow[t]{2}{*}{ Sig. } & \multirow[t]{2}{*}{ Odds ratio } & \multicolumn{2}{|c|}{$\begin{array}{l}95 \% \mathrm{Cl} \\
\text { for } \operatorname{EXP}(\beta)\end{array}$} \\
\hline & & & & Lower & Upper \\
\hline \multicolumn{6}{|c|}{ a. Dependent variable: mobility } \\
\hline Age (years) & 0.057 & 0.0001 & 1.059 & 1.034 & 1.085 \\
\hline \multicolumn{6}{|l|}{ Gender } \\
\hline Male & Reference & & & & \\
\hline Female & 1.640 & 0.007 & 5.156 & 1.564 & 16.997 \\
\hline \multicolumn{6}{|l|}{ Monthly income (Tk) } \\
\hline High-income group & Reference & & & & \\
\hline $\begin{array}{l}\text { Upper-middle- } \\
\text { income group }\end{array}$ & 1.007 & 0.022 & 2.738 & 1.160 & 6.463 \\
\hline $\begin{array}{l}\text { Lower-middle- } \\
\text { income group }\end{array}$ & 0.371 & 0.393 & 1.449 & 0.619 & 3.393 \\
\hline Low-income group & 1.146 & 0.210 & 3.145 & 0.523 & 18.90 \\
\hline $\mathrm{HbA} 1_{c} \%$ & 0.120 & 0.06 & 1.128 & 0.997 & 1.276 \\
\hline \multicolumn{6}{|c|}{ b. Dependent variable: self-care } \\
\hline Age (years) & 0.039 & 0.002 & 1.039 & 1.014 & 1.065 \\
\hline \multicolumn{6}{|c|}{ Family history of diabetes } \\
\hline No & Reference & & & & \\
\hline Yes & -0.867 & 0.001 & 0.420 & 0.250 & 0.706 \\
\hline Don't know & 0.257 & 0.669 & 1.293 & 0.398 & 4.199 \\
\hline $\begin{array}{l}\text { Duration (years) of } \\
\text { diabetes }\end{array}$ & 0.042 & 0.021 & 1.043 & 1.006 & 1.082 \\
\hline \multicolumn{6}{|c|}{ c. Dependent variable: usual activity } \\
\hline \multicolumn{6}{|l|}{ Gender } \\
\hline Male & \multicolumn{5}{|l|}{ Reference } \\
\hline Female & 1.322 & 0.022 & 3.751 & 1.207 & 11.658 \\
\hline \multicolumn{6}{|l|}{ Monthly income (Tk) } \\
\hline $\begin{array}{l}\text { High-income } \\
\text { group }\end{array}$ & Reference & & & & \\
\hline $\begin{array}{l}\text { Upper-middle- } \\
\text { income group }\end{array}$ & 0.974 & 0.024 & 2.648 & 1.136 & 6.173 \\
\hline $\begin{array}{l}\text { Lower-middle- } \\
\text { income group }\end{array}$ & 0.384 & 0.371 & 1.469 & 0.633 & 3.41 \\
\hline $\begin{array}{l}\text { Low-income } \\
\text { group }\end{array}$ & 0.337 & 0.696 & 1.401 & 0.258 & 7.609 \\
\hline \multicolumn{6}{|c|}{ Family history of diabetes } \\
\hline No & Reference & & & & \\
\hline Yes & -0.767 & 0.002 & 0.464 & 0.288 & 0.747 \\
\hline Don't know & 0.618 & 0.335 & 1.855 & 0.528 & 6.520 \\
\hline \multicolumn{6}{|c|}{ d. Dependent variable: pain } \\
\hline Age (years) & 0.050 & 0.0001 & 1.051 & 1.025 & 1.079 \\
\hline \multicolumn{6}{|l|}{ Monthly income (Tk) } \\
\hline $\begin{array}{l}\text { High-income } \\
\text { group }\end{array}$ & Reference & & & & \\
\hline $\begin{array}{l}\text { Upper-middle- } \\
\text { income group }\end{array}$ & 1.034 & 0.015 & 2.811 & 1.227 & 6.441 \\
\hline $\begin{array}{l}\text { Lower-middle- } \\
\text { income group }\end{array}$ & 0.946 & 0.023 & 2.576 & 1.138 & 5.832 \\
\hline
\end{tabular}

Table 2 continued

\begin{tabular}{|c|c|c|c|c|c|}
\hline \multirow[t]{2}{*}{$\begin{array}{l}\text { Independent } \\
\text { variable }\end{array}$} & \multirow[t]{2}{*}{$\beta$} & \multirow[t]{2}{*}{ Sig. } & \multirow[t]{2}{*}{ Odds ratio } & \multicolumn{2}{|c|}{$\begin{array}{l}95 \% \mathrm{Cl} \\
\text { for } \operatorname{EXP}(\beta)\end{array}$} \\
\hline & & & & Lower & Upper \\
\hline $\begin{array}{l}\text { Low-income } \\
\text { group }\end{array}$ & 0.188 & 0.836 & 1.207 & 0.205 & 7.115 \\
\hline \multicolumn{6}{|c|}{ e. Dependent variable: anxiety } \\
\hline \multicolumn{6}{|l|}{ Habitat } \\
\hline Urban & Reference & & & & \\
\hline Rural & -0.588 & 0.042 & 0.555 & 0.315 & 0.978 \\
\hline Semi-urban & 20.449 & 0.999 & 7.60 & 0.0001 & $<0.001$ \\
\hline \multicolumn{6}{|l|}{ Level of education } \\
\hline Illiterate & Reference & & & & \\
\hline $\begin{array}{l}\text { Primary to 8th } \\
\text { grade }\end{array}$ & -0.577 & 0.085 & 0.562 & 0.291 & 1.082 \\
\hline SSC to HSC & -0.446 & 0.228 & 0.640 & 0.310 & 1.321 \\
\hline $\begin{array}{l}\text { Graduate and } \\
\text { postgraduate }\end{array}$ & -0.960 & 0.028 & 0.383 & 0.162 & 0.902 \\
\hline $\mathrm{HbA} 1_{c} \%$ & 0.128 & 0.06 & 1.136 & 0.996 & 1.296 \\
\hline
\end{tabular}

healthcare facilities at the peripheral areas, and on the other hand, the electronic media have reached those areas. People of the peripheral areas who have access to media can also get information on diabetes and its related complications. These are the probable reasons for the satisfactory results in our study relating to the quality of life among the rural people.

Several studies have reported that obesity $[9,11,13]$, type of treatment [10,13], glycemic status [10, 11, 13], and complications/co-morbid conditions $[9,12,13]$ are associated with the quality of life. In the present study, type of treatment, obesity, glycemic status, and acquisition of information were found to be associated with the HR-QoL but not significantly. This result indicates that, in addition to the parameters analyzed in the study, other factors, that need to be studied, were significantly affecting the quality of life in patients with type 2 diabetes and those might be the patients' perspective, ideas, and expectations relating to management of diabetes. With poor glycemic control and higher BMI, the risk of developing diabetes-related complications increases, which causes physical well-being to deteriorate. Besides this, psychological and physiological effects, such as increased anxiety owing to frustration with the inability to manage the condition, are likely to affect one's quality of life.

The study has some limitations. The study being a center and outpatient-based one, its results may not be truly representative of all DM patients. We had also no data on diabetes-related complications/co-morbid 
Table 3 Status of association of independent variables with domains at a glance

\begin{tabular}{|c|c|c|c|}
\hline Domain & Significantly associated variable & Not significantly associated variable & Nagelkerke's $\mathrm{R}^{2}$ \\
\hline Mobility & Age, gender, monthly income & $\begin{array}{l}\text { Habitat, family history of DM, duration of DM, education, } \\
\text { occupation, acquisition of information, BMI, } \mathrm{HbA} 1 \mathrm{C}, \\
\text { prescribed treatment }\end{array}$ & $\begin{array}{l}0.314 \\
\cong 31.4 \%\end{array}$ \\
\hline Self-care & Age, family history of DM, duration of DM & $\begin{array}{l}\text { Gender, habitat, education, occupation, acquisition of informa- } \\
\text { tion, BMI, prescribed treatment, monthly income, } \mathrm{HbA} 1 \mathrm{c}\end{array}$ & $\begin{array}{l}0.268 \\
\cong 26.8 \%\end{array}$ \\
\hline Usual activities & Gender, family history of DM, monthly income & $\begin{array}{l}\text { Age, habitat, duration of DM, education, occupation, acquisi- } \\
\text { tion of information, BMI, prescribed treatment, } \mathrm{HbA} 1 \mathrm{c}\end{array}$ & $\begin{array}{l}0.224 \\
\cong 22.4 \%\end{array}$ \\
\hline Pain/discomfort & Gender, monthly income & $\begin{array}{l}\text { Gender, habitat, family history of DM, duration of DM, educa- } \\
\text { tion, occupation, acquisition of information, BMI, prescribed } \\
\text { treatment, } \mathrm{HbA} 1 \mathrm{c}\end{array}$ & $\begin{array}{l}0.213 \\
\cong 21.3 \%\end{array}$ \\
\hline Anxiety/depression & Habitat, education & $\begin{array}{l}\text { Age, gender, family history of } \mathrm{DM} \text {, duration of } \mathrm{DM} \text {, occupation, } \\
\text { acquisition of information, } \mathrm{BMI}, \mathrm{HbA} 1 \mathrm{c} \text {, prescribed treatment, } \\
\text { monthly income }\end{array}$ & $\begin{array}{l}0.160 \\
\cong 16 \%\end{array}$ \\
\hline
\end{tabular}

Table 4 Multiple Linear regression analysis of EQ-5D index value as a dependent variable with other parameters of the patients $(n=500)$

\begin{tabular}{|c|c|c|c|c|c|}
\hline \multirow{2}{*}{$\begin{array}{l}\text { Predictor } \\
\text { variable }\end{array}$} & \multirow[t]{2}{*}{$B^{a} \pm S E$} & \multirow[t]{2}{*}{ Beta $^{b}$} & \multirow[t]{2}{*}{$P$ value } & \multicolumn{2}{|c|}{$95 \% \mathrm{Cl}$ for $\mathrm{B}$} \\
\hline & & & & Lower & Upper \\
\hline ge (years) & $-0.007 \pm 0.002$ & -0.223 & 0.0001 & -0.010 & -0.004 \\
\hline ender & $-0.280 \pm 0.033$ & -0.398 & 0.0001 & -0.344 & -0.215 \\
\hline Habitat & $0.012 \pm 0.035$ & 0.015 & 0.732 & -0.056 & 0.080 \\
\hline Education & $0.007 \pm 0.003$ & 0.112 & 0.025 & 0.001 & 0.014 \\
\hline Occupation & $-0.012 \pm 0.016$ & -0.034 & 0.451 & -0.045 & 0.020 \\
\hline $\begin{array}{l}\text { Family history } \\
\text { of DM }\end{array}$ & $4.78 \pm 0.0001$ & 0.024 & 0.556 & $<0.0001$ & $<0.0001$ \\
\hline $\begin{array}{l}\text { Duration (years) } \\
\text { of DM }\end{array}$ & $-0.003 \pm 0.002$ & -0.052 & 0.246 & & 0.002 \\
\hline $\begin{array}{l}\text { Monthly } \\
\text { income (Tk) }\end{array}$ & $5.14 \pm 0$ & 0.056 & 0.179 & 0.0001 & $<0.0001$ \\
\hline $\mathrm{HbA} 1_{c} \%$ & $-0.012 \pm 0.008$ & -0.062 & 0.145 & -0.028 & 0.004 \\
\hline $\begin{array}{c}\text { Acquisition of } \\
\text { information }\end{array}$ & $-0.010 \pm 0.036$ & -0.286 & 0.775 & -0.082 & 0.061 \\
\hline $\begin{array}{l}\text { Prescribed } \\
\text { treatment }\end{array}$ & $-0.022 \pm 0.011$ & -0.084 & 0.048 & -0.044 & 0.0001 \\
\hline $\begin{array}{l}\text { Body mass } \\
\text { index }\left(\mathrm{kg} / \mathrm{m}^{2}\right)\end{array}$ & $0.001 \pm 0.002$ & 0.022 & 0.586 & -0.003 & 0.005 \\
\hline
\end{tabular}

Adjusted $\mathrm{R}^{2}=20 \%$; Overall model $\mathrm{F}$ test, $\mathrm{p}=0.0001$

$D M$ diabetes mellitus

a Unstandardized sample regression co-efficient

b Standardized sample regression co-efficient

conditions. Since it was a cross-sectional study, it cannot, therefore, determine causality. Longitudinal studies assessing the natural history of diabetes and the quality of life are needed to draw a solid conclusion on the causal pathway of these associations. Equivalently, we could not collect data for a matching cohort, which could help us compare and find the impact of the disease on our study patients. In this study, the patients self-reported, and the results might not, thus, give the true reflection in all aspects.

The quality of life of patients is an essential factor that affects diabetic management. The present study provides basic information on the quality of life, and the findings indicate that patients with diabetes suffer from moderately poor HR-QoL. The study has several implications. The ultimate diabetic care should, therefore, include the assessment of quality of life in any modality used for treating diabetic patients.

Although this study generated baseline data relating to quality of life of diabetes patients in our country, more studies, with a larger sample-size and with matching cohort, are strongly needed in other parts of Bangladesh for identifying the weaknesses of diabetes management for observing the impact of the disease. To run successful healthcare programs for diabetes patients, we have to include physiotherapy and health educator facilities and also construct available counselors and counseling center. Further longitudinal studies will help researchers and policy-makers to create cartulary effective intervention programs and policy for diabetes patients in Bangladesh.

\section{Conclusions}

The findings of the study suggest that most patients have problems in the domain of pain/discomfort and anxiety/depression, and half of the patients have problems in mobility and usual activities. Age, female gender, income, education, family history and duration of DM, prescribed treatment, and glycemic status are important factors associated with the HR-QoL in patients with type 2 diabetes.

\section{Authors' contributions}

FS: contributed her intellectual ability to conception and design of the research, analysis. and interpretation of data, drafting of the article and revising it critically for important intellectual content, and final approval of the version to be published; FA: contributed her intellectual ability to conception and 
design of the research, analysis, and interpretation of data; SJM: contributed her intellectual ability to conception and design of the research, analysis and interpretation of data; $\mathrm{MAH}$ : contributed his intellectual ability to analysis and interpretation of data; All authors read and approved the final manuscript.

\section{Author details}

${ }^{1}$ Department of Community Nutrition, Bangladesh University of Health Sciences (BUHS), 125/1 Darussalam Mirpur 1, Dhaka 1216, Bangladesh. ${ }^{2}$ BRAC Institute of Global Health, BRAC University, icddr,b campus, 68 Shaheed Tajuddin Ahmed Sharani, Mohakhali, Dhaka 1212, Bangladesh. ${ }^{3}$ Department of Epidemiology, BUHS, Dhaka, Bangladesh. ${ }^{4}$ Department of Biostatistics, BUHS, Dhaka, Bangladesh.

\section{Acknowledgements}

The study was funded by the Diabetic Association of Bangladesh. We acknowledge the physicians, nurses, and other staff members of the Bangladesh Institute of Health Sciences (BIHS) hospital for their cooperation during the study. We thank the study patients with type 2 diabetes. We also acknowledge our colleagues Sharifa Sadia Mahmud, Asmaul Husna Laizu, and Abeda Parvin of the Bangladesh University of Health Sciences (BUHS) for their cooperation in data-collection. We highly acknowledge our respected colleague Mr. M. Shamsul Islam Khan, Advisor, Department of Library and In-Charge, English Foundation Course, Department of Applied Languages and Culture, BUHS, for his guidance in language editing.

\section{Compliance with ethical guidelines}

\section{Competing interests}

The authors declare that they have no competing interests.

Received: 27 January 2014 Accepted: 16 September 2015 Published online: 29 September 2015

\section{References}

1. World Health Organization. Global data on visual impairments, 2010 Geneva: World Health Organization Organization; 2012.

2. Unwin N, Whiting D, Guariguata L, Ghyoot G, Gan D, editors. IDF Diabetes ATLAS. Brussels: International Diabetes Federation; 2012.

3. Hussain A. Diabetes prevention in Bangladesh. Faculty of Medicine UiO: Institute of Health and Society, 2011 May [cited 2013 December]. http://www.med.uio.no/helsam/english/research/news-and-events/ news/2011/diabetes.html.

4. Constitution of the World Health Organization. Handbook of Basic Documents, World Health Organization. 5th ed. Geneva: Palais des Nations; 1952. p. 3-20.

5. DeWalt DA, Rothrock N, Yount S, Stone AA. Evaluation of item candidates: the PROMIS qualitative item review. Med Care. 2007;45(Suppl 5):12-21.
6. Fisher EB Jr, Arfken CL, Heins J, Houston C, Jeffe D, Sykes R. Acceptance of diabetes in adults. In: Gochman DS, editor. Handbook of Health Behavior Research. New York: Plenum Publishing Corp; 1996.

7. Clarke PM, Hayes AJ, Glaszou PG, Scott R, Simes J, Keech AC. Using the EQ-5D index score as a predictor of outcomes in patients with type 2 diabetes. Med Care. 2009:47:61-8.

8. Sakamaki H, Ikeda S, Ikegami N, Uchigata Y, Iwamoto Y, Origasa H, Otani T, Otani Y. Measurement of HRQL using EQ-5D in patients with type 2 diabetes mellitus in Japan. Value Health. 2006;9:47-53.

9. Lee WJ, Song KH, Noh JH, Choi YJ, Jo MW. Health-related quality of life using the EuroQol 5D questionnaire in Korean patients with type 2 diabetes. J Korean Med Sci. 2012;27:255-60.

10. Shim YT, Lee J, Toh MPHS, Tang WE, Ko Y. Health-related quality of life and glycaemic control in patients with type 2 diabetes mellitus in Singapore. Diabet Med. 2012;29:241-8.

11. AlMaskari MY, AIShookri AO, AlAdawi SH, Lin KG. Assessment of quality of life in patients with type 2 diabetes mellitus in Oman. Saudi Med J. 2012;32:1285-90.

12. Papadopoulos AA, Kontodimopoulos N, Frydas A, Ikonomakis E, Niakas D. Predictors of health-related quality of life in type II diabetic patients in Greece. BMC Public Health. 2007;7:186-94.

13. Redekop WK, Koopmanschap MA, Stolk PR, Rutten GEHM, Wolffenbuttel BHR, Niessen LW. Health-related quality of life and treatment satisfaction in Dutch patients with type 2 diabetes. Diabetes Care. 2002;25:458-63.

14. Saleh F, Mumu SJ, Ara F, Begum HA, Ali L. Knowledge and self-care practices regarding diabetes among newly diagnosed type 2 diabetics in Bangladesh: a cross-sectional study. BMC Public Health. 2012;12:1112.

15. EuroQol Group. EuroQol-a new facility for the measurement of health related quality of life. Health Policy. 1990;16:199-208.

16. Dolan P. Modeling valuations for Euroqol Health States. Med Care. 1997:35:1095-108.

17. Haque ANMN. By the numbers: the middle-income matrix. The Daily Star; 2007. November 18 (Editorial).

18. WHO expert consultation. Appropriate body-mass index for Asian populations and its implications for policy and intervention strategies. Lancet. 2004;363:157-63.

\section{Submit your next manuscript to BioMed Central and take full advantage of:}

- Convenient online submission

- Thorough peer review

- No space constraints or color figure charges

- Immediate publication on acceptance

- Inclusion in PubMed, CAS, Scopus and Google Scholar

- Research which is freely available for redistribution

Submit your manuscript at 